УДК 377.121.427

05.13.00 Информатика, вычислительная техника и управление

13.00.00 Педагогические науки

ОБ ОДНОМ ИЗ ПОДХОДОВ К ПОВЫШЕНИЮ МОТИВАЦИИ УЧАЩИХСЯ К ОБРАЗОВАТЕЛЬНОЙ И ВНЕУЧЕБНОЙ ДЕЯТЕЛЬНОСТИ ЗА СЧЕТ РЕЙТИНГОВОЙ СИСТЕМЫ

\author{
Согоян Спартак Сереюжаевич \\ д.п.н. \\ «Гюмрийский педагогически институт \\ им.М.Налбандяна», Армения, Гюмри, \\ П.Севака, 4
}

Дьяченко Роман Александрович

д.т.н.

ФГБОУ «Кубанский государственный

технологический университет»,350072, Россия, г

Краснодар, ул.Московская, 2

Бельченко Илья Владимирович

ФГБОУ «Кубанский государственный

университет»,350040, Россия, г Краснодар,

ул.Ставропольская, 149

Рассматриваются вопросы повышения мотивации учащихся организаций среднего

профессионального образования и высшего профессионального образования к учебной и вне учебной деятельности за счет применения балльнорейтингового подхода к учету достижений. Рассматриваются факторы, оказывающие негативное влияние на учебную и вне учебную деятельность, такие как: развлекательные телепередачи, онлайн игры, социальные сети. Рассматриваются виды деятельности, оказывающие положительное влияние на учебную и внеучебную деятельность, такие как:

волонтерская деятельность, научная деятельность, общественно полезная деятельность.

Анализируются достоинства и недостатки традиционных подходов к увеличению мотивации учащихся на основе трехуровневой стипендии. Рассматриваются вопросы размещения информации о рейтинге учащихся в режиме онлайн на информационных сайтах образовательных организаций и мультимедийных стендах. Рассматриваются вопросы, связанные с «прозрачной» схемой формирования рейтинга учащихся за счет формирования портфолио учащегося. Предложена схема фиксированной стоимостной оценки видов деятельности учащихся в баллах. Предложена формула расчета стипендии с учетом достижений учащегося в учебной и вне учебной, волонтерской деятельности. Приведен пример внешнего вида прототипа
UDC 377.121 .427

Computer science, computer facilities and management

Pedagogical sciences

\section{ON ONE OF THE APPROACHES TO ENHANCING THE MOTIVATION OF STUDENTS TO EDUCATIONAL AND EXTRACURRICULAR ACTIVITIES THROUGH THE RATING SYSTEM}

\author{
Soghoyan Spartak Serezhaevich \\ Dr.Ped.Sci. \\ Gyumri State Pedagogical Institute named \\ after M.Nalbandyan, Armenia, Gyumri, P.Sevak 4
}

Dyachenko Roman Aleksandrovich

Dr.Tech.Sci.

Kuban State Technological University, 350072

Russia, Krasnodar, Moskovskaya, 2

Belchenko Ilya Vladimirovich

Kuban State University, 350040 Russia, Krasnodar, Stavropolskaya, 149

The problems of increasing the motivation of students of organizations of secondary vocational education and higher education to educational and training activities is due to the use of score-rating approach to recording achievements. The article examines factors that have a negative impact on training and outside training activities, such as TV entertainment, online games, social networks. We consider the activities that have a positive impact on the educational and training activities outside, such as volunteer work, scientific work, socially useful activity. We analyze the advantages and disadvantages of traditional approaches to increase the motivation of students on the basis of a three-level scholarships. The article reveals problems of placing information on the ranking of students in online news sites on educational organizations and media stands. The problems associated with the "transparent" scheme of formation of students rated by forming a student's portfolio have been considered as well. We have given a scheme of a fixed valuation of activities of pupils in points and a formula for calculating the scholarships for student achievements in education and trainings, as well as in volunteer activities. An example of the appearance of a prototype automated system for recording pupils' achievements has been presented. The article also shows data on the implementation of the prototype in educational institutions 
автоматизированной системы учета достижений учащихся. Приведены данные о внедрении прототипа в образовательных организациях

КлючевЫе слова: РЕЙТИНГ УЧАЩЕГОСЯ, МОТИВАЦИЯ, ФОРМУЛА РАСЧЕТА, УЧЕТ Keywords: RATING, STUDENT MOTIVATION, ДОСТИЖЕНИЙ FORMULA CALCULATIONS, TAKING INTO ACCOUNT ADVANCES

Doi: 10.21515/1990-4665-122-052

\section{Введение}

Образовательный процесс неразрывно связан с мотивацией учащихся к учебной и вне учебной деятельности.

Учебная деятельность - это вид практической педагогической деятельности, целью которой является человек, владеющий необходимой частью культуры и опыта старшего поколения, представленных учебными программами в форме совокупности знаний и умений ими пользоваться [1].

Внеучебная деятельность - это один из видов деятельности учащихся, направленный на социализацию обучаемых, развитие творческих способностей в внеучебное время [2].

Мотивация - это побуждения, вызывающие активность, определяющие направленность личности.

В настоящее время мотивационный кризис ощущается повседневно. Он ставит под угрозу процесс развития и сам процесс учебной деятельности. От уровня мотивации учащихся зависит не только имидж образовательной организации, но и общий уровень подготовки. С развитием информационных технологий в обществе количество сторонней информации, предоставленной в свободном доступе для учащегося, также возросло. Основными элементами индустрии развлечений, на которые учащиеся тратят большую часть свободного времени, являются:

- социальные сети;

- видео хостинги;

- онлайн игры.

http://ej.kubagro.ru/2016/08/pdf/52.pdf 
C проблемой утраты мотивации учащихся сталкиваются как крупные, так и небольшие образовательные организации.

Существующие решения основаны на выполнении критериев успеваемости учащимися, но подходов к усилению уровня мотивации для обучающихся, выполняющих требования успеваемости, нет. Учащиеся, отвечающие требованиям успеваемости, могут заниматься видами учебной деятельности, выходящими за рамки обязательной составляющей учебы [3].

К таким видам деятельности относятся:

- исследовательская и научная;

- общественно полезная;

- волонтерская.

Схема, отражающая расход свободного времени учащихся представлена на рисунке 1.

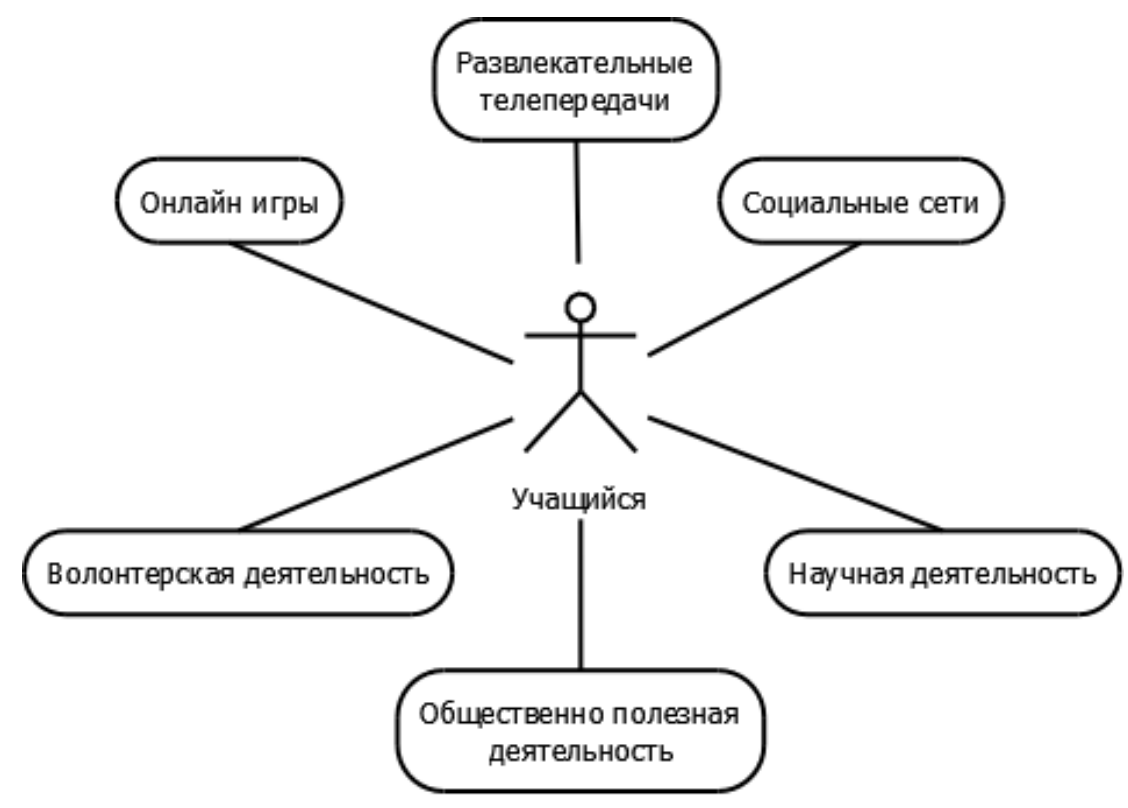

Рисунок 1 - Типовая схема расходования свободного времени учащимися

Таким образом, повышение уровня мотивации учащихся к учебной и вне учебной деятельности за счет перераспределения времени учащегося в общей структуре расходования его свободного времени является актуальной проблемой. 
Целью исследования является разработка системного подхода к повышению уровня мотивации учащихся.

Объектом исследования является процесс повышения мотивации учащихся организаций высшего профессионального образования (ВПО) и среднего профессионального образования (СПО).

Предметом исследования является метод повышения уровня мотивации учащихся за счет внедрения балльно-рейтинговой системы.

Для достижения поставленной цели необходимо решить следующие задачи:

- разработка механизма оценки деятельности учащихся;

- выявление критериев оценки деятельности учащихся;

- разработка механизма публичного отображения рейтинга учащихся.

\section{Предлагаемое решение}

В качестве одного из решений проблем связанных с повышением уровня мотивации учащихся предлагается рейтинговый подход к оценке деятельности.

Рейтинговая система - это совокупность правил, методических указаний и соответствующего математического аппарата, реализованного в программном комплексе, обеспечивающем обработку информации как по количественным, так и по качественным показателям индивидуальной учебной деятельности студентов, позволяющем присвоить персональный рейтинг (интегральную оценку, число) каждому студенту в разрезе любой учебной дисциплины, любого вида занятий, а также обобщенно по ряду дисциплин [4].

В рамках подхода предлагается взять традиционную рейтинговую идеологию оценки успеваемости учащихся и применить ее к более широкому кругу видов учебной и внеучебной деятельности. Это позволит 
обеспечить необходимый уровень мотивации учащихся за счет следующих факторов:

- прозрачный механизм формирования рейтинга;

- отображение рейтинга в открытом доступе в режиме онлайн;।

- формирование портфолио учащегося;

- формирование денежных поощрений в зависимости от рейтинга учащегося.

Схема влияния деятельности учащихся на рейтинг представлена на рисунке 2.

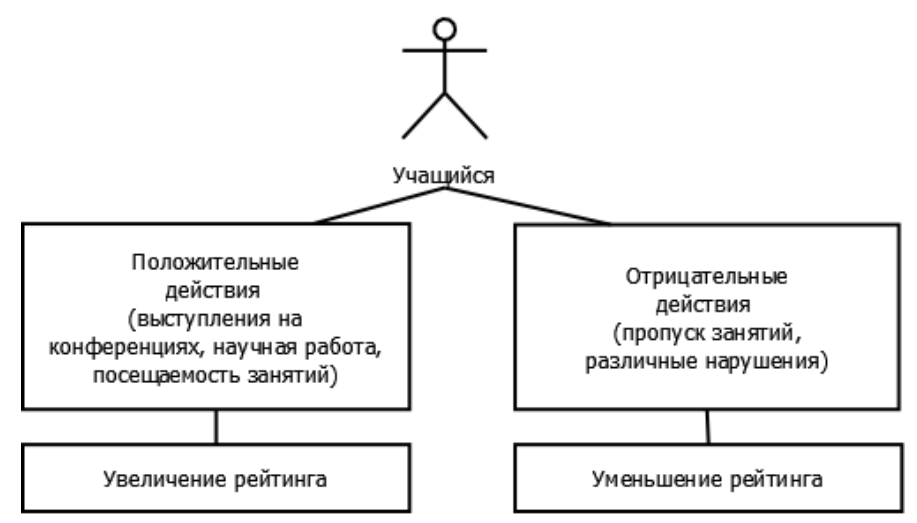

Рисунок 2 - Схема влияния деятельности учащихся на рейтинг

В рамках подхода выделены следующие критерии оценки деятельности учащихся:

- посещение занятий;

- успеваемость;

- участие в конкурсах, конференциях;

- участие в вне учебной и волонтерской деятельности;

- участие в «жизни образовательной организации».

Каждому критерию соответствуют определенные виды деятельности с четко установленной стоимостью в баллах [5]. Пример распределения стоимостей видов деятельности в рамках критерия представлен на рисунке 3. 


\section{Научная работа}

\begin{tabular}{|c|c|}
\hline Вид деятельности & Количество баллов \\
\hline Участие в олимпиаде & 4 \\
\hline Победа в олимпиаде & 10 \\
\hline $\begin{array}{c}\text { Выступление на международной } \\
\text { конференции }\end{array}$ & 7 \\
\hline Публикация в изданиях ВАК & 15 \\
\hline
\end{tabular}

Рисунок 3 - Пример распределения стоимостей видов деятельности в рамках критерия

За нарушения и «неполезную» деятельность предлагается вычитать баллы из общего рейтинга учащегося.

Для прозрачного и честного начисления баллов в рейтинг предлагается сделать портфолио учащихся с перечнем видов деятельности, за которые были начислены баллы. Пример схемы портфолио представлен на рисунке 4.

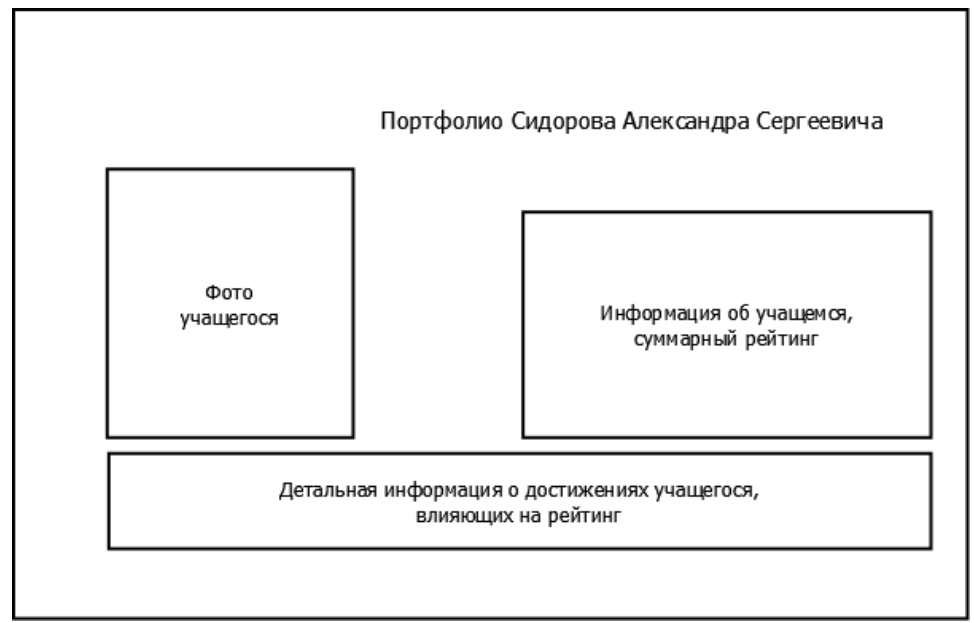

Рисунок 4 - Пример схемы портфолио

Портфолио состоит из информации об учащемся, фотографии, детальной информации о достижениях, влияющих на рейтинг. Прозрачный механизм начисления баллов положительно влияет на уровень мотивации учащихся [6].

Для повышения уровня мотивации предлагается сделать таблицу учащихся по убыванию показателя рейтинга в публичном доступе [7]. http://ej.kubagro.ru/2016/08/pdf/52.pdf 
Отображение рейтинга должно вестись в режиме онлайн на информационном WEB портале образовательной организации, информационных мультимедийных стендах. Пример таблицы рейтинга учащихся представлен на рисунке 5.

Рейтинг учащихся образовательной организации

\begin{tabular}{|l|l|}
\hline ФИО учащегося & Количество баллов \\
\hline Петров А.П. & 870 \\
\hline Сидоров О.Л. & 845 \\
\hline Антосьева Н.И. & 720 \\
\hline Рожнов М.М. & 657 \\
\hline
\end{tabular}

Рисунок 5 - Пример таблицы рейтинга учащихся

В рамках рейтингового подхода к повышению мотивации предлагается отойти от трехуровневой градации стипендии:

- повышенная;

- полу-повышенная;

- обычная.

Размер стипендии зависит от рейтинга учащегося путем применения фиксированного коэффициента для расчета. Пример формулы расчета стипендии при использовании исследуемого подхода представлен на рисунке 6.

$$
\begin{aligned}
& F=k * R, \text { где } \\
& F-\text { размер стипендии, } \\
& k-\text { фиксированный коэффициент повышения, } \\
& R \text { - рейтинг учащегося. }
\end{aligned}
$$

Рисунок 6 - Пример формулы расчета стипендии В рамках подхода был разработан и внедрен прототип информационной системы в Армавирском государственном 
педагогическом университете. Внешний вид главной страницы системы для учащегося представлен на рисунке 7.

\section{Бельченко И.В.}

Группа: А-89

Достижения учащегося

\section{Рейтинг Бельченко И.В.}

\begin{tabular}{|c|c|c|}
\hline Вид деятельности & $\begin{array}{c}\text { Количество } \\
\text { баллов }\end{array}$ & $\begin{array}{c}\text { Подробнее о } \\
\text { достижении }\end{array}$ \\
\hline Участие в олимпиаде & 4 & Открыть \\
\hline Победа в олимпиаде & 20 & Открыть \\
\hline $\begin{array}{c}\text { Выступление на международной } \\
\text { конференции }\end{array}$ & 7 & Открыть \\
\hline
\end{tabular}

Рисунок 7 - Пример главной страницы прототипа системы для учащегося

\section{Заключение и вывод}

В результате исследования был разработан подход для увеличения уровня мотивации учащихся к учебной и вне учебной деятельности за счет введения балльно-рейтинговой системы, являющийся одним из решений проблемы повышения заинтересованности учащихся.

Предложенный подход подходит для использования как малыми, так и большими образовательными организациями. Предложенная прозрачная схема начисления баллов и формирования рейтинга дополнительно повышает уровень мотивации.

Учитывая разнообразие учащихся по интересам, навыкам и умениям в подходе предлагается учитывать несколько критериев при поощрении определенного вида деятельности. Это позволит соревноваться в единой рейтинговой шкале абсолютно разным учащимся. Размещение в открытом доступе рейтинга, изменения в котором происходят в реальном времени, побудит учащихся просматривать информацию о нем, бороться за место в рейтинге. 
На основании вышеизложенного, работа в рамках подхода положительно скажется на качестве образовательного процесса в учебной организации, повышении уровня мотивации учащихся.

\section{Литература}

1. Бельченко B.E. Технология организации Web-сайта учебного заведения // Высшее образование в России. 2014. № 4. С. 97-101.

2. Коновалов Д.П., Дьяченко Р.А., Богданов В.В. Современные средства разработки WEB-приложений. Сравнительный анализ // Сборник III Международной научно-практической конференции молодых ученых, посвященная 52-й годовщине полета Ю.А. Гагарина в космос. 2013. С. 303-306.

3. Фишер А.В., Дьяченко Р.А., Лоба И.С. Организация хранения хронологических данных в базах данных систем мониторинга и прогнозирования // Политематический сетевой электронный научный журнал Кубанского государственного агарного университета. 2012/ № 79. С. 271-280.

4. Дьяченко Р.А., Бельченко И.В., Терехов В.В. Иллюстрация применения метода дельфи для решения задачи выбора направления развития предприятия // Автоматизированные информационные и электроэнергетические системы. 2012. С. 243-244.

5. Шароватов А.С., Лоба И.С., Решетняк М.Г. Разработка алгоритма поиска оптимальной модели // Политематический сетевой электронный научный журнал Кубанского государственного агарного университета. 2012. № 77. С. 413-422.

6. Кучер В.А., Магомадов А.С., Чигликова Н.Д., Дьяченко Р.А. Обеспечение информационной безопасности вычислительной сети с использованием интеллектуальных систем // Политематический сетевой электронный научный журнал Кубанского государственного агарного университета. 2015. № 110. С. 1811-1816.

7. Атрощенко В.А., Руденко М.В., Дьяченко Р.А., Багдасарян Р.Х. К вопросу организация хранения данных в мобильном приложении // Научные труды Кубанского государственного технологического университета. 2014. № 1. С. 189-197.

\section{References:}

1. Bel'chenko V.E. Tehnologija organizacii Web-sajta uchebnogo zavedenija // Vysshee obrazovanie v Rossii. 2014. № 4. S. 97-101.

2. Konovalov D.P., D'jachenko R.A., Bogdanov V.V. Sovremennye sredstva razrabotki WEB-prilozhenij. Sravnitel'nyj analiz // Sbornik III Mezhdunarodnoj nauchnoprakticheskoj konferencii molodyh uchenyh, posvjashhennaja 52-j godovshhine poleta Ju.A. Gagarina v kosmos. 2013. S. 303-306.

3. Fisher A.V., D'jachenko R.A., Loba I.S. Organizacija hranenija hronologicheskih dannyh v bazah dannyh sistem monitoringa i prognozirovanija // Politematicheskij setevoj jelektronnyj nauchnyj zhurnal Kubanskogo gosudarstvennogo agarnogo universiteta. 2012/ № 79. S. 271-280.

http://ej.kubagro.ru/2016/08/pdf/52.pdf 
4. D'jachenko R.A., Bel'chenko I.V., Terehov V.V. Illjustracija primenenija metoda del'fi dlja reshenija zadachi vybora napravlenija razvitija predprijatija // Avtomatizirovannye informacionnye i jelektrojenergeticheskie sistemy. 2012. S. 243-244.

5. Sharovatov A.S., Loba I.S., Reshetnjak M.G. Razrabotka algoritma poiska optimal'noj modeli // Politematicheskij setevoj jelektronnyj nauchnyj zhurnal Kubanskogo gosudarstvennogo agarnogo universiteta. 2012. № 77. S. 413-422.

6. Kucher V.A., Magomadov A.S., Chiglikova N.D., D'jachenko R.A. Obespechenie informacionnoj bezopasnosti vychislitel'noj seti s ispol'zovaniem intellektual'nyh sistem // Politematicheskij setevoj jelektronnyj nauchnyj zhurnal Kubanskogo gosudarstvennogo agarnogo universiteta. 2015. № 110. S. 1811-1816.

7. Atroshhenko V.A., Rudenko M.V., D'jachenko R.A., Bagdasarjan R.H. K voprosu organizacija hranenija dannyh $\mathrm{V}$ mobil'nom prilozhenii // Nauchnye trudy Kubanskogo gosudarstvennogo tehnologicheskogo universiteta. 2014. № 1. S. 189-197. 